Universidade Tecnológica Federal do Paraná - UTFPR

Campus Ponta Grossa - Paraná - Brasil

ISSN: 1981-3686/v. 04, n. 01: p. 01-09, 2010

D.O.I.: $10.3895 / \mathrm{S} 1981-36862010000100001$
Revista Brasileira deTecnologia

Agroindustrial

\title{
ELABORAÇÃO DE BEBIDA LÁCTEA PASTEURIZADA SABOR BACURI ENRIQUECIDA COM PÓLEN
}

\section{ELABORATION OF PASTEURIZED MILK DRINK FLAVORED BACURI ENRICHED WITH POLLEN'S BEES WITHOUT STINGS.}

\author{
Elen Vanessa Costa da Silva ${ }^{1}$; Leanny de Fatima Pinheiro Silva Medeiros ${ }^{2}$; Danielle Barros \\ Monteiro $^{3}$; Gisele Freitas da Silva ${ }^{4}$ \\ 1,2,3 Universidade do Estado do Pará - UEPA - Belém - Brasil elen@ uepa.br \\ ${ }^{4}$ Escola de Educação Tecnológica do Estado do Pará-EETEPA - Tailandia - Brasil \\ giselefresa@yahoo.com.br
}

\begin{abstract}
Resumo
O presente trabalho teve como objetivo elaborar uma bebida láctea pasteurizada a partir do soro de queijo bovino e enriquecer com pólen a fim de acrescentar ao produto um elevado valor protéico e constatar esse enriquecimento através das análises, visto que o valor protéico encontrado no pólen vai além das necessidades humanas de aminoácidos essenciais e do pólen ser ainda pouco utilizado como produto alimentício. Foram elaboradas duas bebidas $A$ e $B$ com as respectivas concentrações de pólen: $2 \%$ e 4\%. Posteriormente foram realizadas análises físicoquímicas, microbiológicas, sensorial, rendimento e custo. As análises físico-químicas mostraram que a bebida A apresentou 84,71\% de umidade, 0,76\% de proteína, 0,49\% de cinzas, 14 de ${ }^{\circ}$ Brix, 4,4 de pH, 0,33\% de acidez, 1,82\% de lipídeos, 12,22\% de carboidratos e 68,3Kcal/100g de valor calórico. Enquanto a bebida B apresentou 82,35\% de umidade, 1,25\% de proteína, 0,55\% de cinzas, 15,8 ${ }^{\circ}$ Brix, 4,0 de pH, 0,55\% de acidez, 2,12\% de lipídeos, 13,96\% de carboidratos $e$ $79,76 \mathrm{Kcal} / 100 \mathrm{~g}$ de valor calórico. As análises microbiológicas mostraram que as bebidas estavam dentro dos padrões exigidos pela legislação vigente. Na análise sensorial, a bebida A obteve aceitação de 80,36\% e a bebida $B$ 77,96\%, não apresentando diferença estatística entre si. Em relação ao custo beneficio a elaboração da bebida lácteas enriquecida com pólen foram economicamente viável.
\end{abstract}

Palavras-chave: proteína; aceitação; regional.

\section{Introdução}

Hoje se observa que os alimentos não possuem como função apenas saciar a fome, também devendo nutrir, fornecendo vitaminas, minerais, aminoácidos ao organismo. Segundo Bazzani et al. (2007) a cada dia que passa o consumidor está em busca de alimentos mais saudáveis, visando contribuir para o alcance de uma dieta de melhor qualidade. A população está preocupada com as conseqüências que os estilos de vida e seus hábitos alimentares têm sobre a saúde, sendo que a 
escolha e consumo inadequado dos alimentos podem ocasionar uma deficiência nutricional em qualquer período de vida.

O soro proveniente da fabricação de queijo possui um alto valor nutricional; porém muitas vezes é descartado no meio ambiente gerando uma serie de prejuízos a natureza. $\mathrm{O}$ reaproveitamento é uma maneira de aumentar a rentabilidade e a competitividade dos lacticínios, pois além de evitar o gasto com o tratamento de efluentes, existe a possibilidade de lucrar coma fabricação de outros produtos (NEVES, 1993 citado por SILVA, 2005).

No Brasil, principalmente na Região Amazônica, existem algumas espécies de fruteiras domesticadas ou cultivadas com grande potencial agroindustrial e ainda pouco exploradas. Dentre essas espécies destaca-se o bacuri (Platonia insignis Mart.) por sua importância econômica nas regiões Norte e Nordeste (BEZZERA et al., 2005). Esta fruta é uma das mais populares do Pará, seu maior produtor, pois possui sabor e odor agradáveis e é apreciado ao natural e ainda como sorvete, creme, refresco, iogurte (FARIA; COSTA, 1998).

Sendo assim, o mercado está repleto de alimentos, que além de boa qualidade e bom paladar carregam vários nutrientes. Esses tipos de alimentos são conhecidos como alimentos funcionais. Dentre esses alimentos destaca-se o pólen, alimento bastante protéico e altamente nutritivo, sendo importante para o bom funcionamento do organismo. Portanto o desenvolvimento de novos produtos enriquecido com esse alimento visa proporcionar uma alimentação mais saudável e que atenda as necessidades nutricionais da população, visto que é cada vez maior a preocupação do consumidor com a origem dos alimentos e com seu valor nutricional. Dessa forma, o presente trabalho teve como objetivo elaborar uma bebida a partir do soro de leite bovino e enriquecer com pólen a fim acrescentar ao produto um elevado valor protéico e viabilizar esse enriquecimento através das análises físico-química e sensorial.

\section{Material e métodos}

O soro de leite bovino foi obtido da produção de queijo tipo minas frescal. A matéria-prima foi devidamente armazenada sobre temperatura de $4{ }^{\circ} \mathrm{C}$. As análises físico-química e sensorial foram realizadas no laboratório de Química da Universidade do Estado do Pará - CCNT/Belém-PA. As análises microbiológicas e foram realizadas no Laboratório de Microbiologia da Universidade Federal do Pará (UFPA). Após vários testes, definiu-se a formulação padrão (ingredientes e suas respectivas quantidades percentuais) como pode ser observado na Tabela 1. 
Tabela 1 - Composição da bebida sabor bacuri enriquecida com pólen

\begin{tabular}{ccc}
\hline Componentes & Bebida com 2\% de pólen & Bebida com 4\% de pólen \\
\hline Soro & $60 \%$ & $50 \%$ \\
Polpa de Bacuri & $8 \%$ & $10 \%$ \\
Pólen & $2 \%$ & $4 \%$ \\
Água & $19 \%$ & $23 \%$ \\
Açúcar & $11 \%$ & $13 \%$ \\
Soro & $60 \%$ & $50 \%$ \\
\hline
\end{tabular}

\section{Elaboração das bebidas}

Foram realizados estudos preliminares para elaboração das bebidas com testes parcialmente baseados na metodologia proposta por Abreu (1999), embasando uma formulação que proporcionasse a elaboração de uma bebida aceitável organolepticamente e com um bom valor protéico aceitável.

Para elaboração da bebida foi utilizado soro obtido da dessora de queijo tipo minas frescal. Em seguida foi realizada a pasteurização da matéria-prima a $72{ }^{\circ} \mathrm{C}$ por 15 segundos (pasteurização rápida) e resfriamento. Posteriormente foi feita adição de pólen e homogeneização em liquidificador industrial, envasada em seguida em garrafas de vidro de $500 \mathrm{~mL}$. Por fim, foi realizada a e pasteurização do produto final a $72{ }^{\circ} \mathrm{C}$ por 15 segundos e refrigeração em temperatura de $4{ }^{\circ} \mathrm{C}$.

\section{Análises físico-químicas}

A caracterização físico-química dos produtos elaborados consistiu na determinação do teor de umidade, proteínas, lipídeos, resíduo mineral fixo, $\mathrm{pH}$, acidez, ${ }^{\circ} \mathrm{Brix}$, carboidratos e valor calórico de acordo com a os métodos analíticos da Association of official Analitical ChemistsAOAC (1997) e do Instituto Adolfo Lutz (1985).

- Umidade: Foi realizada em estufa a $70{ }^{\circ} \mathrm{C}$, até peso constante.

- Proteínas: Foi determinado pelo método de Kjeldahl, utilizando aparelho digestor.

- Lipídeos: O teor de gordura foi realizado pelo método de Soxhlet utilizando éter de petróleo como solvente.

- Cinzas: A amostra foi carbonizada e, em seguida calcinada em mufla a $450{ }^{\circ} \mathrm{C}$ até peso constante.

- Valor calórico: Determinou-se conforme equação 1:

$$
\text { Valor calórico }=(\text { Proteína } \mathrm{x} 4)+(\text { Carboidrato x } 4)+(\text { Gordura } \times 9)
$$

- Carboidrato: Para a determinação de carboidratos utiliza-se a somatória dos teores de proteína, gordura, umidade e cinzas, de acordo com a equação 2 .

$$
\text { Carboidrato }=100-(\text { proteína }+ \text { gordura }+ \text { umidade }+ \text { cinzas })
$$


- pH: Foi determinado através de leitura direta em pHmetro digital, calibrado com solução tampão de 4,0 e 7,0 .

- ${ }^{\circ}$ Brix: Utilizou-se refratômetro para medição do ${ }^{\circ}$ Brix das bebidas

- Acidez: A determinação foi realizada através de titulação com $\mathrm{NaOH} 0,1 \mathrm{~N}$, utilizando a fenolftaleína como indicador.

Análises microbiológicas

As análises microbiológicas realizadas foram de contagem de aeróbios mesófilos, coliformes a $35{ }^{\circ} \mathrm{C}$ e $45{ }^{\circ} \mathrm{C}$. Foram realizadas em duplicata, de acordo com a metodologia determinada por Vanderzant e Splittstoesser, (1992) e os resultados foram analisados segundo a legislação vigente Brasil (2001).

\section{Análise sensorial}

Os testes de análise sensorial foram realizados, após 24 horas de elaboração das bebidas no horário compreendido entre 14h:00 e 16h:00, com um grupo formado por 30 provadores nãotreinados de ambos os sexos e idade entre 16 e 35 anos.

As amostras foram codificadas com bebida A (2\% de pólen) e B (com $4 \%$ de pólen). Foram servidas geladas em copos descartáveis de $50 \mathrm{~mL}$ acompanhadas por água e biscoito de água e sal no intervalo de uma degustação para a outra.

Aplicou-se de acordo com Dutcosky (1996), o teste de aceitação estruturada de 9 pontos, cujas extremidades são ancoradas pelos termos: gostei muitíssimo (9) e desgostei muitíssimo (1), e teste de intenção de compra apresentando 5 alternativas utilizando a ficha.

\section{Análise estatística}

Foi realizado também análise de variância e o teste de Tukey ao nível de 5\% através do programa estatístico BioEstat (AYRES et al., (2007).

\section{Análise de rendimento e custo}

O rendimento foi determinado através do cálculo da relação entre a quantidade do produto final e a quantidade inicial da matéria-prima. E o levantamento do custo de produção, obtido a partir de cada um dos ingredientes, na elaboração do produto final (VIEIRA et al., 1994). 


\section{Resultados e discussão}

Resultado das análises de soro

Com os resultados apresentados na Tabela 2 pode-se observar que o soro é considerado tipo doce e apresentou acidez de $11^{\circ} \mathrm{D}$ estando assim dentro dos limites estipulados.

Tabela 2 - Resultado da análise do soro de queijo.

\begin{tabular}{cc}
\hline Soro de queijo & Valor \\
\hline $\mathrm{pH}$ & 6,45 \\
Acidez & $11^{\circ} \mathrm{D}$ \\
\hline
\end{tabular}

O valor máximo estipulado para acidez do soro doce é de $12^{\circ} \mathrm{D}$. Fora desse limite a acidez denuncia soro mal conservado, com alta contaminação microbiana e impróprio para o consumo (LOBATO, 2008). Cunha et al. (2008) ao elaborar uma bebida láctea usou soro com acidez de $10,66^{\circ} \mathrm{D}$ e o $\mathrm{pH}$ foi 6,23 , valores estes bem semelhantes ao encontrado para elaboração das bebidas enriquecidas com pólen.

\section{Análises físico-químicas}

A Tabela 3 mostra o resultado das análises físico-químicas da bebida láctea sabor bacuri com $2 \%$ de pólen (A) e bebida láctea sabor bacuri com $4 \%$ de pólen (B), bem como os valores da legislação de bebidas lácteas não fermentadas (BRASIL, 2005).

Tabela 3: Resultado da análise físico-química da bebida A e B.

\begin{tabular}{cccc}
\hline Análises & Bebida A & Bebida B & BRASIL, (2005) \\
\hline Calorias (Kcal/100g) & $68,3 \pm 0,134^{\mathrm{a}}$ & $79,76 \pm 0,947^{\mathrm{b}}$ & - \\
Carboidrato (\%) & $12,22 \pm 0,106^{\mathrm{a}}$ & $13,96 \pm 0,226^{\mathrm{b}}$ & - \\
Proteínas (\%) & $0,76 \pm 0,062^{\mathrm{a}}$ & $1,25 \pm 0,004^{\mathrm{b}}$ & Min. 1 \\
Lipídeos (\%) & $1,82 \pm 0,035^{\mathrm{a}}$ & $2,12 \pm 0,002^{\mathrm{b}}$ & - \\
Umidade (\%) & $84,71 \pm 0,049^{\mathrm{a}}$ & $82,35 \pm 0,198^{\mathrm{b}}$ & - \\
Cinzas (\%) & $0,49 \pm 0,007^{\mathrm{a}}$ & $0,55 \pm 0,035^{\mathrm{a}}$ & - \\
Acidez (ac. lático) & $0,33 \pm 0,028^{\mathrm{a}}$ & $0,55 \pm 0,026^{\mathrm{b}}$ & - \\
pH & 4,4 & 4,0 & - \\
Brix & 14 & 15,8 & \\
\hline
\end{tabular}

Com relação ao teor de lipídeos apenas a bebida B conseguiu atingir o valor mínimo exigido pela legislação, fato que pode estar relacionado com a maior adição de pólen, que possui de 1 a $14 \%$ de lipídeo em sua composição (LENGLER, 1999). Consequentemente apresentou também maior valor calórico, diferenciando-se estatisticamente da bebida A. As duas amostras apresentaram valor de lipídeos superior ao resultado de Faria e Lima (2006), que elaboraram bebida a base de soro sabor taperabá e encontraram teor de $0,52 \%$ de lipídeo.

Os teores de proteína das bebidas apresentaram diferença estatística entre si. A bebida A apresentou valor inferior ao exigido pela legislação Brasil (2005), que se destina a bebida a base de leite. Este fato pode ser explicado por se tratar de uma bebida elaborada com soro, que até então era desperdiçado, sendo de grande importância a agregação de valor. 
A bebida A apresentou maior teor de umidade, diferenciando-se estatisticamente da bebida B. Tal fato pode ser explicado devido a bebida A apresentar em sua formulação um percentual maior de soro, contribuindo para o resultado.

O teor de cinza da bebida A foi 0,49\% e a bebida B foi 0,55\% sendo estatisticamente iguais. De acordo com Colto e Couto (2002) a quantidade de cinzas no pólen pode estar entre 0,7 e 7\% podendo variar conforme a planta de origem. Tal fato se explica também quando comparado com os valores de cinzas das bebidas elaboradas por Farias e Lima (2006) que encontraram valor de 0,32\% e não utilizaram o pólen em sua composição.

O percentual de acidez na bebida A foi inferior a bebida B e estatisticamente diferentes. Isso pode ter ocorrido devido a maior quantidade de pólen na bebida B, já que o mesmo apresenta uma acidez elevada devido a ação de enzimas que produzem ácido glicônico, justificando assim o valor do pH encontrado (NOGUEIRA-NETO, 1998).

\section{Análises microbiológicas}

Os resultados das análises microbiológicas da bebida láctea sabor bacuri enriquecidas com $2 \%$ de pólen (A) e bebida láctea sabor bacuri com 4\% de pólen (B) para bactérias mesófilas e coliformes a $35{ }^{\circ} \mathrm{C}$ e $45{ }^{\circ} \mathrm{C}$ estão apresentados na Tabela 4.

Tabela 4 - Resultados das análises microbiológicas das bebidas

\begin{tabular}{lccc}
\hline \multicolumn{1}{c}{ Análises } & Bebida A & Bebida B & BRASIL (2001) \\
\hline Coliformes Totais $\left(35^{\circ} \mathrm{C}\right)(\mathrm{NMP} / \mathrm{g})$ & $<3$ & $<3$ & 10 \\
Coliformes fecais $\left(45^{\circ} \mathrm{C}\right)(\mathrm{NMP} / \mathrm{g})$ & $<3$ & $<3$ & 5 \\
Bactérias mesófilas (UFC/g) & $1,0 \times 10^{1}$ & $1,0 \times 10^{1}$ & $1,5 \times 10^{5}$ \\
\hline
\end{tabular}

De acordo com os resultados obtidos pode-se considerar que as bebidas estão aptas ao consumo, pois estão dentro dos padrões estabelecidos pela legislação vigente (BRASIL, 2001). Os resultados encontrados são decorrentes do uso de toucas, máscaras, lavagem e sanitização de utensílios e mãos, apresentando assim condições higiênico-sanitárias satisfatórias, sendo portanto um produto inócuo e que não oferece riscos a saúde do consumidor.

\section{Análise sensorial}

O teste de aceitabilidade aplicado com a intenção de verificar o quanto este novo produto fora apreciado por seus avaliadores tem seu resultado descrito na Tabela 5.

Tabela 5- Resultado da análise sensorial, intenção de compra e aceitabilidade.

\begin{tabular}{lccc}
\hline Bebida & Média & Aceitabilidade & Intenção de compra \\
\hline Bebida A & $7,2 \pm 0,44^{\mathrm{a}}$ & $80,36 \%^{\mathrm{a}} \pm 4,19^{\mathrm{a}}$ & $89,3 \% \pm 4,24^{\mathrm{a}}$ \\
Bebida B & $7,0 \pm 0,28^{\mathrm{a}}$ & $77,96 \%^{\mathrm{a}} \pm 2,88^{\mathrm{a}}$ & $83,3 \% \pm 4,24^{\mathrm{a}}$ \\
\hline
\end{tabular}


Comprovou-se que as amostras A e B obtiveram uma boa aceitação e não apresentaram diferença estatística entre si. A bebida A obteve maior média $(7,2)$ onde sua aceitabilidade foi de $77,40 \%$ em relação a bebida B que apresentou média 7 correspondendo a 77,96\%. Desta forma as notas das duas bebidas correspondem ao termo gostei regularmente.

Quanto a intenção de compra, 89,3\% dos provadores comprariam o produto A e 83,3\% o produto $\mathrm{B}$, não havendo diferença estatística entre as duas amostras.

Segundo Paschoal (2002) para ser considerada aceitável qualquer amostra analisada é necessário que se obtenham resultados com no mínimo de $70 \%$ de aprovação.

\section{Rendimento}

A bebida A apresentou rendimento de $89,97 \%$ e a bebida B de 90,85\%. Observa-se que houve um rendimento satisfatório, as perdas existentes foram apenas nas etapas de pasteurização da matéria prima e produto final.

\section{Análise do custo}

$\mathrm{O}$ custo de produção da bebida láctea $\mathrm{A}$ e $\mathrm{B}$, por unidade contendo $500 \mathrm{~mL}$, foi de $\mathrm{R} \$ 0,54$ (cinquienta e quatro centavos), mostrando ser um produto de baixo custo quando comparado com marcas comerciais de bebidas lácteas que variam de $\mathrm{R} \$ 1,50$ a 2,00.

\section{Conclusão}

Pode-se concluir que o pólen contribui para o aumento do valor protéico, fazendo com que a bebida láctea a partir de soro (B) atingisse o valor mínimo de proteína permitido pela legislação de bebidas lácteas.

Os valores encontrados nas análises microbiológicas mostraram que os produtos estavam aptos para o consumo, pois não apresentaram contaminação, nem risco a saúde do consumidor.

$\mathrm{Na}$ análise sensorial, as bebidas atingiram valores acima de $70 \%$ de aceitação e intenção de compra, assim como rendimento satisfatório superior a $80 \%$ e custo relativamente baixo. Dessa forma recomenda-se que produtos de fácil acesso como bebidas lácteas, sorvetes, biscoitos e iogurtes sejam enriquecidos com pólen.

\footnotetext{
Abstract

This study aimed to develop a drink pasteurized milk from bovine whey and rich with pollen in order to add the product a high protein value and finds that enrichment throughout the analysis because the quality protein found in pollen goes beyond human needs of essential aminoacids, however, the pollen is still underutilized as a foodstuff. Were prepared two drinks A and B with their pollen concentrations: $2 \%$ and $4 \%$, respectively. Later tests were performed physical-chemical,
} 
microbiological, sensory, efficiency and cost analysis. The physical-chemical analysis showed that the drink A had $84.71 \%$ moisture, $0.76 \%$ protein, $0.49 \%$ ash, $14 \circ$ Brix, $\mathrm{pH} 4.4,0.33 \%$ acidity, $1.82 \%$ lipid, $12.22 \%$ carbohydrates and $68.3 \mathrm{kcal} / 100 \mathrm{~g}$ caloric value. While the drink B showed $82.35 \%$ moisture, $1.25 \%$ protein, $0.55 \%$ ash, $15.8 \circ$ Brix, $\mathrm{pH} 4.0,0.55 \%$ acidity, $2.12 \%$ of lipids, carbohydrates $13.96 \%$ and $79.76 \mathrm{kcal} / 100 \mathrm{~g}$ caloric value. Microbiological analysis showed that the drinks were within the standards required by legislation. In sensory analysis the beverage gained acceptance of $80.36 \%$ and $77.96 \%$ B drink, no significant difference between them. Regarding the cost-benefit the elaboration of milk drinks enriched with pollen were viable.

Key-words: protein; acceptance; regional.

\section{Referências}

ABREU. L.R. Tecnologia do leite e derivados. Lavras: UFLA/FAEPE, 1999.

ASSOCIATION OF OFFICIAL AGRICULTURAL CHEMISTS. Official methods of analysis. 16. ed. Washington, DC, 1997.

AYRES, M.; AYRES JR, M; AYRES, D.L.; SANTOS, A.S. BioEstat 5.0: aplicações estatísticas nas áreas das ciências biológicas e médicas. $5^{a}$ Edição (2007). Belém: Sociedade Civil Mamirauá, Imprensa Oficial do Estado do Pará; Brasília: CT Brasil.

BAZZANI, C.S.R.; VILLELA, S.H.M.; ANTUNES, A.M.; SANTOS, V.C.P; BENSUASKI, B.M. Desenvolvimento e caracterização de um iogurte de soja enriquecido com cálcio, sabor amora. Revista Higiene Alimentar, v.21. n.155, out, 2007.

BEZERRA, G.S.A.; MAIA, G.A.; FIGUEIREDO, R.W.; FILHO, M.S. Boletim do centro de pesquisas e processamento de alimentos. CEPPA, Curitiba, v.23. jan/jun. 2005.

BRASIL. Ministério da Saúde. Agência nacional de Vigilância Sanitária. Resolução CNNPA. N ${ }^{\circ} 12$ de 02 de Janeiro de 2001. RegulamentoTécnico sobre os Padrões Microbiológicos para Alimentos. Diário Oficial da União, Brasília, DF, 27 jan 2001.

BRASIL. Ministério da Agricultura Pecuária e Abastecimento. Instrução Normativa n॰16, de 23 de agosto de 2005. Regulamento Técnico de Identidade e Qualidade de Bebidas Lácteas. Diário Oficial da União, Brasília, DF, 27 jul 2005 .

COUTO, R.H.N.; COUTO, L.A. Apicultura: manejo e produção. 2 ed. Jaboticabal: FUNEP, 2002.

CUNHA, T.M.; CASTRO, F.P.; BARRETO, P.L.M.; BENEDET, H.D.; PRUDENCIO, E.S. Avaliação físico-química, microbiológica e reológica de bebida láctea e leite fermentado adicionados de probióticos. Disponível em: <http: //www.uel.br/proppq/semina. Acesso em 02 de out de 2008.

FARIAS, L.J.G.; COSTA, C.M.L. Tópicos especiais em tecnologia de produtos naturais. Belém: UFPA, Pará, NUMA. Série Poema, 1998.

FARIAS, F.C.; LIMA, L.D.S. Elaboração de bebida pasteurizada a partir do soro do leite bovino com características funcionais e sabor fruta regional. 2006 Trabalho de Conclusão de curso (Graduação em Tecnologia Agroindustrial - ênfase em Alimentos)- Universidade do Estado do Pará, Paragominas, 2006, 58p.

INSTITUTO ADOLPHO LUTZ. Normas Analíticas do Instituto Adolpho Lutz: Métodos Químicos para Análise de Alimentos. 2. ed. São Paulo, 1985. 533p.

LENGLER, S. Pólen apicola. Santa Maria: [s.n], 1 ed, 1999.

LOBATO, V. Tecnologia de fabricação de derivados do leite na propriedade rural, 2008. Disponível em : <http: //www.editora.ufla.br/extencao. Acesso em 25 de set de 2008. 
NEVES, E.C.A. Tecnologia de leite e derivados. Belém: [s.n], 2001.

NOGUEIRA-NETO, N.P. Vida e criação de abelhas indígenas sem ferrão. São Paulo: Nogueirapis, 1998.

PACHOAL, V. Alimentos para a saúde. São Paulo: [s.n.], 2002.

VANDERZANT, C.; SPLITTSTOESSER, D. F. 1992. Compendium of methods for microbiological examination of foods. 3.ed. Washington, DC: American Public Health Associatio. 914 pp.

VIEIRA, A.L.A.; CRUZ, A.G.; BARBIN, D.F.; VAN DENDER, A.G.F. Soro de queijo: atitudes e conhecimento do consumidor. In: 7 Simpósio Latino Americanos (SLACA), 2007. Campinas: [sn], 2007.

\section{Dados dos autores}

Nome completo: Elen Vanessa Costa da Silva

Filiação institucional: Universidade do Estado do Pará

Departamento: Departamento de Tecnologia de Alimentos

Função ou cargo ocupado: Professora Assistente I

Titulação: Mestre em Ciencia e Tecnologia de alimentos

Endereço: Conjunto Médici I, Tv benevides, 105, Belem Pará Brasil, CEP: 66620460

Telefones para contato: (91)32316019, 81140062

e-mail:elen@uepa.br

Nome completo: Leanny de Fátima Pinheiro Silva Medeiros

Filiação institucional: UEPA

Titulação: Graduada em Tecnologia de Alimentos

e-mail: leannypinheiro@hotmail.com

Nome completo: Danielle Barros Monteiro

Filiação institucional: UEPA

Titulação: Graduada em Tecnologia de Alimentos

e-mail:daniellebmonteiro@hotmail.com

Nome completo: Gisele Freitas da Silva

Filiação institucional: Escola de Educação Tecnológica do Estado do Pará Tailandia

Departamento: Agroindustria

Função ou cargo ocupado: Professora do curso Tecnico em Agroindustria

Titulação: Especialista em Agronegócio

Telefones para contato: 91-81392977

e-mail:giselefresa@yahoo.com.br 